\title{
Е.И. Кайбичева
}

\section{ПРОЦЕССЫ НОВОЙ ИНДУСТРИАЛИЗАЦИИ В ПРОСТРАНСТВЕ КРУПНЫХ И КРУПНЕЙШИХ ГОРОДОВ ${ }^{1}$}

\begin{abstract}
В России процессы новой индустриализации приобретают свою специфику, во многом связанную с качественной разнородностью ее экономического пространства. Одним из оплотов новой индустриализации являются крупные и крупнейтие города. В статье рассмотрено содержание понятий «новая индустриализачия», «город». Представлено обобщение существующих подходов $\kappa$ оценке процессов новой индустриализации. Автором на основе анализа имеющейся статистической информации дана характеристика процессов новой индустриализации в крупных и крупнейтих городах страны. Показано, что значение промышленности для экономики этих территорий сохраняется. Для оценки процессов новой индустриализачии с качественной точки зрения предложена интеграция имеющейся статистической информации для расчета показателей в разрезе крупных и крупнейших городов.

Ключевые слова: новая индустриализация, регион, региональная экономика, экономическое пространство, город.
\end{abstract}

\section{Введение}

Мир постепенно приходит к осознанию того, что определяющая роль промышленности в экономическом развитии сохранится и в будущем. Возврат промышленных предприятий, развитие промышленности на качественно новой технологической основе - вот составляющие процессов новой индустриализации, которые набирают обороты в различных странах, в том числе и в России.

Для нашей страны процессы новой индустриализации в непростых экономических условиях приобретают первостепенное значение. Именно с возрождением промышленности ведущие экономисты, политологи и политики связывают будущее развитие страны и дальнейший экономический рост (см., например, [1-3]). Россия уже находится на этом пути. В 2011 г. Владимир Путин в выступлении на VII Ежегодном бизнес-форуме Деловой России отметил, что «у России есть все для индустриального, технологического прорыва» [4]. Ведущая роль в этих процессах отводится крупным городам, особенно тем из них, которые имеют сложившуюся промышленную специализацию. Цель настоящей статьи - охарактеризовать процессы

\footnotetext{
${ }^{1}$ Статья подготовлена при поддержке РФФИ (грант № 18-010-00789 А «Разработка методического инструментария исследования экономики нового индустриального города в условиях трансформации пространственной организации экономической деятельности»).
} 
новой индустриализации в пространстве крупных и крупнейших городов России.

\section{Понятие «город» и его сущность}

Город как сложное явление с давних пор является объектом изучения для многих дисциплин - экономики, градоведения, градостроительства, социологии и т.д. В литературе сложилось несколько точек зрения на идентификационную сущность города. Сторонники количественной теории (К. Бюхер) определяют город исходя из количественного критерия численности его жителей. Согласно этой теории «городом называется значительное и длительное скопление людей на сравнительно незначительной территории» [5. С. 4]. Политически-административная теория (Райт, Ренуap) относит к городам населенные пункты, которым «государственной властью присвоены особые административные права» [5. С. 5]. Социальная теория города (Н.П. Анциферов) дает следующее его определение «город есть место, приспособленное для общежития социальной группы сложного характера, внутренне дифференцированной и получившей определенную правовую форму» [6. С. 28].

Каждый город имеет свою индивидуальность. Нельзя говорить о существовании двух абсолютно одинаковых городов. Вместе с тем изучение большого числа разнородных объектов весьма затруднительно. Поэтому ученые предложили различные основания, используя которые можно выделить группы похожих городов. Одним из таких оснований стала численность населения города (его размер).

В зависимости от численности населения города делятся на малые (до 50 тыс. жителей), средние (50-100 тыс.), большие (100-250 тыс.), крупные (250-1000 тыс.), крупнейшие (1-3 млн жителей), сверхкрупные (свыше 3,0 млн человек) [7].

\section{Новая индустриализация: теоретические аспекты исследования}

Несмотря на то, что сам термин «новая индустриализация» появился еще в 60-70-х гг. XX в., единого его понимания в научной литературе не сложилось и по сей день.

«В узком понимании новая индустриализация рассматривается как восстановление в России на новой технической основе промышленного производства после глубокого спада 1990-х годов» [8. С. 179]. Однако значительная часть исследователей придерживаются более широкого понимания новой индустриализации. По их мнению, речь идет не просто о количественном восстановлении промышленного производства, а о его качественной трансформации на новой технологической основе. «Новая индустриализация страны - глубокие структурные сдвиги в пользу наукоемких отраслей промышленности, в первую очередь обрабатывающей» [9]. Существует точка зрения, в рамках которой новая индустриализация свя- 
зывается как с созданием новых производств, так и с трансформацией традиционных для той или иной территории видов экономической деятельности.

Под новой индустриализацией в рамках данной статьи понимается «синхронный процесс не только создания новых секторов наукоемкой, высокотехнологичной продукции, но и эффективного инновационного обновления традиционных секторов экономики при согласованных качественных изменениях во всей системе общественных отношений» [10. С. 145-146].

\section{Подходы к оценке процессов новой индустриализации}

Прежде чем рассматривать развитие процессов новой индустриализации в городах, необходимо определиться с тем, какие подходы следует для этого использовать.

Как правило, исследователи делают упор на анализе статистических данных. Тогда возникает вопрос: какие показатели нужно и можно применять для характеристики новой индустриализации?

Первый подход, с которым соглашаются подавляющее большинство исследователей, состоит в использовании показателей численности занятых в отдельных видах экономической деятельности (разделы ОКВЭД - C, D, E), объема отгруженных товаров собственного производства, выполненных работ и услуг собственными силами по отдельным видам экономической деятельности и его динамики, индексов промышленного производства и т.д.

Но эти показатели не дают возможности учесть качественные характеристики промышленности. Например, за 2009-2016 гг. в России наблюдался рост объемов отгруженных товаров собственного производства, выполненных работ и услуг собственными силами по разделам ОКВЭД - C, D, E. O каком развитии промышленности это свидетельствует - о качественном, основанном на использовании новых технологий, или о количественном, связанном с увеличением объема заказов и (или) стоимости продукции?

Поэтому мы считаем возможным использовать эти показатели только в сопряжении с другими, например с данными по выпуску промышленной продукции в натуральном выражении.

Второй подход связывает характеристику процессов новой индустриализации с развитием высокотехнологичных производств. В этом случае можно использовать следующие показатели, имеющиеся в настоящий момент в открытом доступе на сайте Федеральной службы государственной статистики:

- доля высокотехнологичных и наукоемких отраслей экономики в ВВП;

- доля высокотехнологичных и наукоемких отраслей экономики в ВРП;

- производство высокотехнологичных видов промышленной продукции;

- индекс производства по высокотехнологичным обрабатывающим видам экономической деятельности. 
Ответ на вопрос, что следует относить к высокотехнологичным производствам, можно найти на официальном сайте Федеральной службы государственной статистики. «Критерием отнесения к высокотехнологичным отраслям является высокий уровень технологического развития, определяемый по отношению затрат на НИОКР к валовой добавленной стоимости» [11]. Росстатом определен закрытый перечень видов экономической деятельности, которые включаются в состав высокотехнологичных, среднетехнологичных высокого уровня отраслей. В состав высокотехнологичных видов деятельности в соответствии с действующей статистической методологией включаются производство фармацевтической продукции; производство офисного оборудования и вычислительной техники; производство электронных компонентов, аппаратуры для радио, телевидения и связи; производство медицинских изделий; средств измерений, контроля, управления и испытаний; оптических приборов, фото- и кинооборудования, часов; производство летательных аппаратов, включая космические. К среднетехнологичным видам деятельности относятся химическое производство, сюда же входит производство фармацевтической продукции; производство машин и оборудования; производство электрических машин и электрооборудования; производство автомобилей, прицепов и полуприцепов; строительство и ремонт судов; производство железнодорожного подвижного состава (локомотивов, трамвайных моторных вагонов и прочего подвижного состава); производство мотоциклов и велосипедов; производство прочих транспортных средств и оборудования, не включенных в другие группировки [11].

Второй подход предполагает, что при характеристике технологического уровня промышленности территории также следует обратить внимание на размещение на ней предприятий, выпускающих уникальную продукцию, конкурентоспособную на мировом рынке, на наличие инновационных производств и т.д.

Таким образом, основные подходы к характеристике процессов новой индустриализации базируются на оценке роли промышленности (или отдельных ее отраслей, как правило высокотехнологичных) в экономике соответствующей территории и их распределении по ней.

\section{Качественные и количественные характеристики новой индустриализации в крупных и крупнейших городах}

Следует отметить, что оценка развития процессов новой индустриализации в городах осложнена рядом трудностей, связанных в том числе и с отсутствием необходимой статистической информации. Это касается в первую очередь показателей, характеризующих инновационное и технологическое развитие промышленности.

Рассматривая роль городов в процессах новой индустриализации, мы пришли к выводу, что большинство ученых делают ставку на крупные города (см., например, [12]). 
Это подтверждается цифрами. Среди 83 субъектов РФ (без учета Республики Крым и г. Севастополя) в 61 присутствуют крупные и крупнейшие города. Именно они в ряде субъектов РФ обеспечивают основной вклад в объемы промышленного производства (приложение).

Доля промышленности крупных и крупнейших городов страны в российских показателях объема отгруженных товаров собственного производства, выполненных работ и услуг собственными силами приведена в таблице.

\section{Вклад крупных и крупнейших городов в российские показатели объема отгруженных товаров собственного производства, выполненных работ и услуг собственными силами за 2005, 2015 гг., \% ${ }^{1}$}

\begin{tabular}{c|c|c|c}
\hline Год & $\begin{array}{c}\text { Добыча полезных } \\
\text { ископаемых }\end{array}$ & $\begin{array}{c}\text { Обрабатывающие } \\
\text { производства }\end{array}$ & $\begin{array}{c}\text { Производство и распределе- } \\
\text { ние электроэнергии, } \\
\text { газа и воды }\end{array}$ \\
\hline 2005 & 20,3 & 54,1 & 61,4 \\
\hline 2015 & $13,7^{*}$ & 52,3 & 53,2 \\
\hline
\end{tabular}

Без учета данных, которые не публикуются в целях обеспечения конфиденциальности первичных статистических данных, полученных от организаций, в соответствии с Федеральным законом от 29.11.07 № 282-Ф3 «Об официальном статистическом учете и системе государственной статистики в Российской Федерации» (ст. 4, п. 5; ст. 9, п. 1).

Заметим, что реальный вклад крупных и крупнейших городов в соответствующие российские показатели выше, поскольку при расчетах не использовались данные, которые не публикуются в целях обеспечения конфиденциальности первичных статистических данных, полученных от организаций, в соответствии с Федеральным законом от 29.11.07 № 282-Ф3 «Об официальном статистическом учете и системе государственной статистики в Российской Федерации».

При этом крупные и крупнейшие города концентрируют на своей территории $6,7 \%$ от числа действующих в стране организаций добычи полезных ископаемых, 13,8\% предприятий обрабатывающих производств и $18,2 \%$ организаций, занимающихся производством и распределением электроэнергии, газа и воды. Сопоставление количества предприятий, действующих на территории крупных и крупнейших городов, с их вкладом в российские объемы промышленного производства (см. таблицу), дает возможность сделать вывод, что крупные и крупнейшие города являются точкой притяжения наиболее успешных и активных компаний, играющих заметную роль в экономике региона.

Можно отметить, что доля крупных и крупнейших городов в российском объеме отгруженных товаров собственного производства, выполненных работ и услуг собственными силами в 2015 г. по сравнению с 2005 г. сократилась. Это свидетельствует о том, что территории идут по пути диверсификации своей экономики, выноса промышленных предприятий за свои пределы. Однако промышленность сохраняет свое значение для их

\footnotetext{
${ }^{1}$ Составлено автором по данным Росстата $[13,14]$.
} 
развития. По итогам 2015 г. крупные и крупнейшие города обеспечивали более половины объема отгруженных товаров собственного производства, выполненных работ и услуг собственными силами по видам деятельности «Обрабатывающие производства», «Производство и распределение электроэнергии, газа и воды».

Остановимся на характеристике качественной составляющей сконцентрированной в крупных и крупнейших городах промышленности. Для начала сопоставим данные о доле высокотехнологичных и наукоемких отраслей экономики в ВРП субъекта РФ с его хозяйственной специализацией и наличием на его территории крупных и крупнейших городов.

По итогам 2014 г. в десятку лидеров по показателю «доля продукции высокотехнологичных и наукоемких отраслей в валовом региональном продукте» вошли Тульская, Калужская области, г. Санкт-Петербург, Республика Бурятия, Ульяновская, Новгородская, Нижегородская области, Пермский край, Кировская область, Чувашская Республика. Среди аутсайдеров - Республика Коми, Республика Дагестан, Оренбургская, Липецкая, Белгородская, Тюменская, Сахалинская области, Ханты-Мансийский автономный округ-Югра, Ненецкий и Ямало-Ненецкий автономные округа. Таким образом, если в число лидеров попали субъекты, которые существенным образом зависят от обрабатывающей промышленности, что подтверждается ее вкладом в показатели валового регионального продукта, то в числе аутсайдеров оказались субъекты, ориентированные в своем экономическом развитии на добычу полезных ископаемых. Объясняется такое положение вещей весьма просто, а именно методикой расчета показателя, в которой к высокотехнологичным относятся преимущественно отрасли обрабатывающих производств.

На территории всех субъектов - аутсайдеров (за исключением Сахалинской области) присутствуют крупные и (или) крупнейшие города. Среди лидеров наличием крупных городов могут похвастаться девять из десяти субъектов. Таким образом, само наличие или отсутствие крупных и (или) крупнейших городов на территории субъекта РФ не предопределяет успешного освоения новых технологий и их применения в производстве промышленной продукции.

Более глубокое и детальное изучение качественных параметров развития промышленности в крупных и (или) крупнейших городах затруднено в связи с отсутствием необходимой статистической информации.

Итак, мы можем сделать вывод, что имеющиеся в открытом доступе статистические данные позволяют охарактеризовать развитие промышленности на территории города с количественной точки зрения. Для рассмотрения качественных параметров имеющейся информации недостаточно. Поэтому для того, чтобы рассмотреть значение крупных и крупнейших городов в процессах новой индустриализации, следует расширить перечень статистических показателей, дополнив их теми, с помощью которых можно охарактеризовать инновационное и технологическое развитие сконцентрированной на их территории промышленности. В противном 
случае значение ряда городов может быть недооценено или переоценено. Как следствие, возможно неверное (не отвечающее реальному положению дел) распределение ресурсов между различными территориями страны и предприятиями. Поэтому совершенствование информационной базы важно и с управленческой точки зрения.

\section{Совершенствование информационной базы характеристики процессов новой индустриализации}

Для характеристики процессов новой индустриализации можно использовать информационную базу, которая в настоящий момент уже имеется в органах государственной статистики. Речь идет о сведениях, содержащихся в формах федерального статистического наблюдения № 1 (технология) «Сведения о разработке и использовании передовых производственных технологий» (утверждена приказом Росстата от 05.08.2016 № 391); № 4 (инновация) «Сведения об инновационной деятельности организации» (утверждена приказом Росстата от 05.08.2016 № 391), № 2-МП (инновация) «Сведения о технологических инновациях малого предприятия» (утверждена приказом Росстата от 03.08.2015 № 357). На базе перечисленных форм с учетом внесения соответствующих изменений в программные средства обработки первичной информации в разрезе крупных и крупнейших городов могут быть рассчитаны следующие показатели, характеризующие развитие промышленности с качественной точки зрения:

- доля предприятий и организаций города, самостоятельно осуществляющих разработку технологических инноваций;

- объем инновационных товаров, работ, услуг;

- объем инновационных товаров, работ, услуг, вновь внедренных или подвергавшихся значительным технологическим изменениям в течение последних трех лет;

- число разработанных передовых производственных технологий ${ }^{1}$ и др.

\section{Заключение}

Крупные и крупнейшие города, являющиеся территорией сосредоточения промышленных гигантов и инновационных и высокотехнологичных компаний, являются участниками набирающих силу процессов новой индустриализации. Промышленность, несмотря на развитие других секторов экономики, продолжает сохранять свое значение. Сконцентрированные на территории крупных и крупнейших городов промышленные предприятия

\footnotetext{
1 «Под передовыми производственными технологиями понимаются технологии и технологические процессы (включая необходимое для их реализации оборудование), управляемые с помощью компьютера или основанные на микроэлектронике и используемые при проектировании, производстве или обработке продукции (товаров и услуг) (в соответствии с международными рекомендациями в области статистического измерения науки, технологий и инноваций, Руководство Фраскати 1993, Москва, 1995)» [15].
} 
обеспечивают более половины российского объема отгруженных товаров собственного производства, выполненных работ и услуг собственными силами по видам деятельности «Обрабатывающие производства», «Производство и распределение электроэнергии, газа и воды».

Попытки оценить процессы перестройки промышленности на качественно новой технологической основе в городах связаны с рядом трудностей. Одной из них является отсутствие необходимой статистической информации в открытом доступе. Решение проблемы видится в интеграции имеющейся первичной информации для расчета дополнительных показателей, характеризующих инновационное и технологическое развитие промышленности в крупных и крупнейших городах России.

\section{Литература}

1. Кульков В.М. Новая индустриализация в контексте экономического развития России // Экономика. Налоги. Право. 2015. № 2. С. 81-85.

2. Силин Я.П., Анимица Е.Г., Новикова Н.В. Перед вызовами третьей волны индустриализации: страна, регион // Известия Уральского государственного экономического университета. 2016. № 3. С. 14-25.

3. Тертышный C.A. Высокотехнологичная индустриализация российской экономики XXI века: pro et contra // Новая индустриализация России. Теоретические и управленческие аспекты: коллективная монография. СПб. : РОСТ, 2014. С. 30-36.

4. Выступление Владимира Путина на VII Ежегодном бизнес-форуме Деловой России. URL: http://www.inesnet.ru/2011/05/vii-ezhegodnyj-biznes-forum-delovoj-rossii-ivstrecha-s-v-v-putinym/

5. Велихов Л.А. Основы городского хозяйства. Общее учение о городском хозяйстве. М. ; Л. : Государственное изд-во, 1928. Ч. 1. 216 с.

6. Анщиферов Н.П. Пути изучения города как социального организма: Опыт комплексного подхода. Л. : «Сеятель» Е.В. Высоцкого, 1926. 151 с.

7. Градостроительный кодекс РФ: федер. закон от 7 мая 1998 г. № 73-Ф3 // КонсультантПлюс : справ. правовая система. URL: http://www.consultant.ru

8. Новиков B.A. К вопросу о «новой индустриализации» в России // Вестник КГУ им. Н.А. Некрасова. 2012. № 6. С. 179-181.

9. Примаков E. Нам нужна новая индустриализация // Российская газета. 09.06.2012. URL: https://rg.ru/2012/06/09/primakov.html

10. Романова O.A. Инновационное развитие промышленного региона в контексте новой индустриализации // Шумпетеровские чтения. Пермь: Изд-во Перм. нац. исслед. политех. ун-та, 2013. № 1. С. 145-149.

11. Об утверждении Методики расчета показателей «Доля продукции высокотехнологичных и наукоемких отраслей в валовом внутреннем продукте» и «Доля продукции высокотехнологичных и наукоемких отраслей в валовом региональном продукте субъекта Российской Федерации» : Приказ Росстата от 14.01.2014 № 21. URL: http://www.consultant.ru/document/cons_doc_LAW_158370/

12. Дворядкина Е.Б. Новая индустриализация и местное самоуправление // Новая индустриализация: мировое, национальное, региональное измерение : материалы Междунар. науч.-практ. конф. (Екатеринбург, 6 декабря 2016 г.) : в 2 т. Екатеринбург : Издво Урал. гос. экон. ун-та, 2016. Т. 1. С. 100-103.

13. Регионы России. Основные социально-экономические показатели городов. 2006. URL: http://www.gks.ru/.

14. Регионы России. Основные социально-экономические показатели городов. 2016. URL: http://www.gks.ru/ 
15. Об утверждении статистического инструментария для организации федерального статистического наблюдения за деятельностью в сфере образования, науки, инноваций и информационных технологий : Приказ Росстата от 05.08.2016 № 391. URL: http://www.consultant.ru/document/cons_doc_LAW_203560

Приложение

Вклад крупных и крупнейших городов в показатели объема отгруженных товаров собственного производства, выполненных работ и услуг собственными силами соответствующих субъектов РФ за 2015 г., \% ${ }^{1}$

\begin{tabular}{|c|c|c|c|c|}
\hline Субъект РФ & Город & $\begin{array}{c}\text { Добыча } \\
\text { полезных } \\
\text { ископа- } \\
\text { емых }\end{array}$ & $\begin{array}{c}\text { Обрабаты- } \\
\text { вающие } \\
\text { производ- } \\
\text { ства }\end{array}$ & $\begin{array}{c}\text { Производство и } \\
\text { распределение } \\
\text { электроэнергии, } \\
\text { газа и воды }\end{array}$ \\
\hline \multicolumn{5}{|c|}{ Центральный федеральный округ } \\
\hline Белгородская область & Белгород & 0,1 & 11,9 & 74,1 \\
\hline Брянская область & Брянск & 0,5 & 47,6 & 76,4 \\
\hline Владимирская область & Владимир ${ }^{*}$ & 2,7 & 19,7 & 66,4 \\
\hline Воронежская область & Воронеж & 5,1 & 42,2 & 58,6 \\
\hline Ивановская область & Иваново & - & 43,5 & 71,8 \\
\hline Калужская область & Калуга & $\ldots^{* *}$ & 47,7 & 72,9 \\
\hline Костромская область & Кострома & 20,6 & 41,6 & 27,9 \\
\hline Курская область & Курск & $\ldots^{* *}$ & 52,9 & 26,8 \\
\hline Липецкая область & Липецк & 26,5 & 78,3 & 89,3 \\
\hline Орловская область & Орел & 15,8 & 50,4 & 78,9 \\
\hline Рязанская область & Рязань & 19,3 & 79,2 & 64,2 \\
\hline Смоленская область & Смоленск & ${ }^{*{ }^{* *}}$ & 34,6 & 26,3 \\
\hline Тамбовская область & Тамбов & $\ldots^{* *}$ & 43,1 & 83,9 \\
\hline Тверская область & Тверь & $\ldots^{* *}$ & 40,0 & 21,0 \\
\hline Тульская область & Тула & 25,8 & 49,0 & 36,8 \\
\hline Ярославская область & Ярославль & 10,2 & 57,4 & 72,4 \\
\hline г. Москва & г. Москва & 100,0 & 100,0 & 100,0 \\
\hline \multicolumn{5}{|c|}{ Северо-Западный федеральный округ } \\
\hline Республика Карелия & Петрозаводск & 2,2 & 18,2 & 63,7 \\
\hline $\begin{array}{l}\text { Архангельская область } \\
\text { (включая Ненецкий АО) }\end{array}$ & Архангельск ${ }^{*}$ & 0,0 & 9,7 & 43,1 \\
\hline \multirow{2}{*}{ Вологодская область } & Вологда & 0,0 & 67,6 & 32,4 \\
\hline & Череповец & 0,0 & 98,3 & 1,7 \\
\hline Калининградская область & Калинград & 89,8 & 58,1 & 87,9 \\
\hline Мурманская область & Мурманск & ${ }^{{ }^{* * *}}$ & 44,5 & 21,1 \\
\hline г. Санкт-Петербург & $\begin{array}{l}\text { г. Санкт- } \\
\text { Петербург }\end{array}$ & 100,0 & 100,0 & 100,0 \\
\hline \multicolumn{5}{|c|}{ Южный федеральный округ } \\
\hline \multirow{3}{*}{ Краснодарский край } & Краснодар & 24,5 & 35,1 & 70,5 \\
\hline & Сочи & 0,5 & 1,1 & 11,5 \\
\hline & Новороссийск & 0,1 & 6,1 & 2,0 \\
\hline Астраханская область & Астрахань & 84,7 & 76,8 & 78,4 \\
\hline Волгоградская область & Волгоград & 93,4 & 63,9 & 51,5 \\
\hline
\end{tabular}

${ }^{1}$ Составлено автором по данным Росстата $[11,15]$. 


\begin{tabular}{|c|c|c|c|c|}
\hline Субъект РФ & Город & $\begin{array}{c}\text { Добыча } \\
\text { полезных } \\
\text { ископа- } \\
\text { емых }\end{array}$ & $\begin{array}{c}\text { Обрабаты- } \\
\text { вающие } \\
\text { производ- } \\
\text { ства } \\
\end{array}$ & $\begin{array}{c}\text { Производство и } \\
\text { распределение } \\
\text { электроэнергии, } \\
\text { газа и воды }\end{array}$ \\
\hline & Вожский & $\ldots^{* *}$ & 25,2 & 37,0 \\
\hline \multirow{2}{*}{ Ростовская область } & Ростов-на-Дону & $\ldots{ }^{*}$ & 42,7 & 27,2 \\
\hline & Таганрог & - & 9,6 & 3,0 \\
\hline \multicolumn{5}{|c|}{ Северо-Кавказский федеральный округ } \\
\hline Республика Дагестан & Махачкала & 35,4 & 27,7 & 13,0 \\
\hline $\begin{array}{l}\text { Республика Северная } \\
\text { Осетия - Алания }\end{array}$ & Владикавказ & 96,9 & 80,3 & 88,5 \\
\hline Чеченская Республика & Грозный & 99,9 & 23,3 & 67,7 \\
\hline Ставропольский край & Ставрополь & 2,2 & 16,1 & 10,2 \\
\hline \multicolumn{5}{|c|}{ Приволэсский федеральньій округ } \\
\hline \multirow{2}{*}{$\begin{array}{l}\text { Республика Башкорто- } \\
\text { стан }\end{array}$} & Уфа & 69,7 & 52,7 & 42,3 \\
\hline & Стерлитамак & 0,0 & 8,4 & 10,1 \\
\hline Республика Марий Эл & Йошкар-Ола & 79,8 & 32,8 & 61,6 \\
\hline Республика Мордовия & Саранск & 4,0 & 44,7 & 75,7 \\
\hline \multirow[b]{2}{*}{ Республика Татарстан } & Казань & 0,4 & 20,9 & 14,6 \\
\hline & $\begin{array}{l}\text { Набережные } \\
\text { Челны }\end{array}$ & 0,1 & 13,5 & 12,6 \\
\hline Удмуртская Республика & Ижевск & 1,1 & 50,5 & 79,9 \\
\hline Чувашская Республика & Чебоксары & 10,3 & 52,0 & 48,8 \\
\hline Пермский край & Пермь & 4,4 & 57,0 & 50,9 \\
\hline Кировская область & Киров $^{*}$ & 6,5 & 42,7 & 70,6 \\
\hline Нижегородская область & $\begin{array}{l}\text { Нижний } \\
\text { Новгород }\end{array}$ & 14,3 & 29,5 & 59,0 \\
\hline Оренбургская область & Оренбург & 20,4 & 38,7 & 56,1 \\
\hline Пензенская область & Пенза & $\ldots *$ & 48,6 & 73,8 \\
\hline \multirow{2}{*}{ Самарская область } & Самара & 3,2 & 25,8 & 39,5 \\
\hline & Тольятти & 0,0 & 45,1 & 24,5 \\
\hline Саратовская область & Саратов & 64,1 & 41,0 & 23,5 \\
\hline Ульяновская область & Ульяновск & 0,0 & 71,1 & 73,3 \\
\hline \multicolumn{5}{|c|}{ Уральский федеральныий округ } \\
\hline Курганская область & Курган & - & 74,2 & 90,2 \\
\hline \multirow{2}{*}{ Свердловская область } & Екатеринбург & 0,7 & 23,2 & 35,6 \\
\hline & Нижний Тагил & 9,3 & 12,6 & 3,9 \\
\hline \multirow{3}{*}{ Тюменская область } & Тюмень & 0,1 & 34,1 & 61,4 \\
\hline & Сургут & 0,2 & 75,5 & 41,0 \\
\hline & Нижневартовск & 2,8 & 2,8 & 10,6 \\
\hline \multirow{2}{*}{ Челябинская область } & Челябинск & 3,9 & 37,4 & 55,5 \\
\hline & Магнитогорск & 1,7 & 35,3 & 8,2 \\
\hline \multicolumn{5}{|c|}{ Сибирский федеральный округ } \\
\hline Республика Бурятия & Улан-Удэ & 0,0 & 82,7 & 45,1 \\
\hline Алтайский край & Барнаул & - & 28,8 & 49,3 \\
\hline Забайкальский край & Чита & 0,7 & 30,4 & 46,1 \\
\hline Красноярский край & Красноярск & 1,8 & 35,2 & 29,4 \\
\hline Иркутская область & Иркутск & 0,0 & 23,7 & 6,6 \\
\hline \multirow{2}{*}{ Кемеровская область } & Кемерово & 0,3 & 20,1 & 27,7 \\
\hline & Новокузнецк & 18,8 & 44,9 & 17,1 \\
\hline
\end{tabular}




\begin{tabular}{|c|c|c|c|c|}
\hline Субъект РФ & Город & $\begin{array}{c}\text { Добыча } \\
\text { полезных } \\
\text { ископа- } \\
\text { емых }\end{array}$ & $\begin{array}{c}\text { Обрабаты- } \\
\text { вающие } \\
\text { производ- } \\
\text { ства }\end{array}$ & $\begin{array}{c}\text { Производство и } \\
\text { распределение } \\
\text { электроэнергии, } \\
\text { газа и воды }\end{array}$ \\
\hline Новосибирская область & Новосибирск & 3,9 & 63,7 & 88,2 \\
\hline Омская область & Омск & 6,3 & 95,0 & 91,1 \\
\hline Томская область & Томск & 0,9 & 60,5 & 68,3 \\
\hline \multicolumn{5}{|c|}{ Дальневосточный федеральный округ } \\
\hline $\begin{array}{l}\text { Республика Саха } \\
\text { (Якутия) }\end{array}$ & Якутск & 3,8 & 71,0 & 60,4 \\
\hline Приморский край & Владивосток & 3,6 & 50,8 & 44,7 \\
\hline \multirow[b]{2}{*}{ Хабаровский край } & Хабаровск & 0,1 & 29,2 & 61,0 \\
\hline & $\begin{array}{l}\text { Комсомольск-на- } \\
\text { Амуре }\end{array}$ & - & 47,7 & 18,4 \\
\hline
\end{tabular}

По городскому округу.

** Данные не публикуются в целях обеспечения конфиденциальности первичных статистических данных, полученных от организаций, в соответствии с Федеральным законом от 29.11.07 № 282-Ф3 «Об официальном статистическом учете и системе государственной статистики в Российской Федерации» (ст. 4, п. 5; ст. 9, п. 1).

Kaibicheva E.I., Department of regional, municipal economy and management, Ural State University of Economics (Ekaterinburg, Russian Federation). E-mail: Catherine.kai@mail.ru

\section{NEW INDUSTRIALIZATION IN THE SPACE OF CITIES}

Keywords: new industrialization, region, regional economy, economic space, city.

New industrialization in Russia has its specific features, reflected great diversity of its economic space. As cities are an integral part of an economic space the author considers them as a base for new industrialization. The paper discusses the essence of the concepts "city", "new industrialization". The author uses official statistic information to characterize trends of new industrialization in large Russian cities. It is shown that the process of new industrialization is very important for its economic development. Special statistic information ought to be calculated in order to characterize quality trends of new industrialization.

\section{References}

1. Kul'kov V.M. Novaya industrializaciya v kontekste ekonomicheskogo razvitiya Rossii // Ekonomika. Nalogi. Pravo. 2015, no 2, pp. 81-85.

2. Silin YA.P., Animitsa E.G., Novikova N.V. Pered vyzovami tret'ey volny industrializacii: strana, region // Izvestiya Ural'skogo gosudarstvennogo ekonomicheskogo universiteta. 2016, no 3, pp. 14-25.

3. Tertyshnyy S.A. Vysokotehnologichnaya industrializaciya rossiyskoy ekonomiki XXI veka: pro et contra // Novaya industrializaciya Rossii. Teoreticheskie i upravlencheskie aspekty: kollektivnaya monografiya. SPb. : NPK «ROST», 2014. pp. 30-36.

4. Vystuplenie Vladimira Putina na VII Ezhegodnom biznes-forume Delovoy Rossii. URL: http://www.inesnet.ru/2011/05/vii-ezhegodnyj-biznes-forum-delovoj-rossii-i-vstrechas-v-v-putinym/

5. Velihov L.A. Osnovy gorodskogo hozyaystva. Obshchee uchenie o gorodskom hozyaystve. Moskva- Leningrad: Gosudarstvennoe izd-vo, 1928. P. 1. 216 p.

6. Anciferov N.P. Puti izucheniya goroda kak social'nogo organizma: Opyt kompleksnogo podhoda. Leningrad: «Seyatel'» E. V. Vysockogo, 1926. 151 p.

7. Gradostroitel'nyy kodeks [Elektronnyy resurs] : feder. zakon ot 7 maya 1998 g. № 73FZ // // KonsultantPlus : sprav. pravovaya sistema. URL: http://www.consultant.ru 
8. Novikov V.A. K voprosu o «novoy industrializacii» v Rossii // Vestnik KGU im. N.A. Nekrasova. 2012, no 6, pp. 179-181.

9. Primakov E. Nam nuzhna novaya industrializaciya // Rossiyskaya gazeta. 09.06.2012. URL: https://rg.ru/2012/06/09/primakov.html

10. Romanova O.A. Innovacionnoe razvitie promyshlennogo regiona $\mathrm{v}$ kontekste novoy industrializacii // SHumpeterovskie chteniya. Perm': Izd-vo Permskogo nacional'nogo issledovatel'skogo politehnicheskogo universiteta. 2013, no 1, pp. 145-149.

11 . Ob utverzhdenii Metodiki rascheta pokazateley «Dolya produkcii vysokotehnologichnyh $\mathrm{i}$ naukoemkih otrasley v valovom vnutrennem produkte» $\mathrm{i}$ «Dolya produkcii vysokotehnologichnyh i naukoemkih otrasley v valovom regional'nom produkte sub"ekta Rossiyskoy Federacii» : Prikaz Rosstata ot 14.01.2014 № 21. URL: http://www.consultant.ru/ document/cons doc LAW 158370/

12. Dvoryadkina E.B. Novaya industrializaciya i mestnoe samoupravlenie // Novaya industrializaciya: mirovoe, nacional'noe, regional'noe izmerenie: materialy mezhdunar. nauch.prakt. konf. (Ekaterinburg, 6 dekabrya 2016 g.) : v 2 p. Ekaterinburg : Izd-vo Ural. gos. ekon. un-ta, 2016, P. 1, pp. 100-103.

13. Regiony Rossii. Osnovnye social'no-ekonomicheskie pokazateli gorodov, 2006. URL: http://www.gks.ru/

14. Regiony Rossii. Osnovnye social'no-ekonomicheskie pokazateli gorodov, 2016. URL: http://www.gks.ru/

15. Ob utverzhdenii statisticheskogo instrumentariya dlya organizacii federal'nogo statisticheskogo nablyudeniya za deyatel'nost'yu v sfere obrazovaniya, nauki, innovaciy i informacionnyh tehnologiy : Prikaz Rosstata ot 05.08.2016 № 391. URL: http://www.consultant.ru/document/cons_doc_LAW_203560

\section{For referencing:}

Kaibicheva E.I. Processy novoj industrializacii v prostranstve krupnyh i krupnejshih gorodov [New industrialization in the space of cities]. Vestnik Tomskogo gosudarstvennogo universiteta. Ekonomika - Tomsk State University Journal of Economics, 2018, no 42, pp. 61-72. 